\section{Metabolic alkalosis and hyperlactataemia}

We describe a case of metabolic alkalosis associated with a severe hyperlactataemia.

\section{Case report}

A 61 year old woman was admitted with a 10 day history of vomiting. She had suffered from flatulence and abdominal discomfort for several years. Magnesium trisilicate had been her only medication. On examination she was salt depleted and hypotensive, supine blood pressure was $90 / 50 \mathrm{~mm} \mathrm{Hg}$ and pulse 80 beats/min, and obvious signs of pyloric stenosis were present. There was no clinical or radiological evidence of chronic lung disease.

Laboratory results on admission were: haemoglobin concentration $80 \mathrm{~g} / \mathrm{l}$; packed cell volume 0.29 ; mean corpuscular volume $68 \mathrm{fl}$; white cell count $16.3 \times 10^{9} / 1$; albumin concentration $40 \mathrm{~g} / 1$; total protein $76 \mathrm{~g} / \mathrm{l}$; bilirubin $12 \mathrm{mmol} / 1$; aspartate aminotransferase activity $17 \mathrm{U} / \mathrm{l}$, sodium concentration $133 \mathrm{mmol} /$; potassium $2.2 \mathrm{mmol} / 1$; chloride $35 \mathrm{mmol} / 1$; magnesium $2.3 \mathrm{mmol} / 1$; urea $28 \mathrm{mmol} / 1$; $\mathrm{pH} 7.8$; pressure of carbon dioxide $\left(\mathrm{PCO}_{2}\right) 4.7 \mathrm{kPa}$; pressure of oxygen $\left(\mathrm{Po}_{2}\right) 11 \cdot 1 \mathrm{kPa}$; and bicarbonate concentration $53 \mathrm{mmo} / \mathrm{l}$. Her anion gap, calculated as (sodium + potassium)-(bicarbonate+chloride), was increased at $47 \mathrm{mmol} / \mathrm{l}$ (reference range in our laboratory $12-20 \mathrm{mmol} / \mathrm{l}$ ). Subsequently her blood lactate concentration was measured as $27 \mathrm{mmol} / \mathrm{l}$ using an enzymatic kit method (Sigma Chemical Co Ltd, Poole, Dorset). Ketone bodies were not detected.

Initial treatment consisted of 41 isotonic saline $(0.9 \%)$ containing $100 \mathrm{mmol}$ potassium given over the first 20 hours. Cimetidine was given intravenously in a dose of $200 \mathrm{mg}$ every six hours. Nasogastric aspiration was started and produced 1.91 fluid, $\mathrm{pH} 2 \cdot 0$, during the first 20 hours. After this time the rate of potassium infusion was increased to $40 \mathrm{mmol} / \mathrm{h}$, resulting in a rise in serum potassium concentration from $2.8 \mathrm{mmol} / \mathrm{l}$ to $4.2 \mathrm{mmol} / \mathrm{l}$ within three hours. A bicarbonate

Blood gas results and inspired air oxygen concentration on admission and during recovery

\begin{tabular}{|c|c|c|c|c|c|c|c|}
\hline & \multicolumn{7}{|c|}{ Hours after admission } \\
\hline & 0 & 10 & 20 & 27 & 34 & 44 & 46 \\
\hline $\begin{array}{l}\text { Approximate } \\
\text { oxygen co } \\
\text { centration } \\
\text { inspired } \\
\text { air }(\%) \\
\mathrm{pH} \\
\mathrm{PcO}_{2}(\mathrm{kPa}) \\
\mathrm{PO}_{2}(\mathrm{kPa}) \\
\mathrm{Bicarbonate}^{2}\end{array}$ & $\begin{array}{c} \\
4 \\
7 \cdot 80 \\
4 \cdot 7 \\
11 \cdot 1\end{array}$ & $\begin{array}{c}\text { A } \\
7.55 \\
7.9 \\
5.9\end{array}$ & $\begin{array}{c}\text { A } \\
7.56 \\
7.7 \\
5.5\end{array}$ & $\begin{array}{c}60 \\
7.54 \\
8.8 \\
17 \cdot 2\end{array}$ & $\begin{array}{r}60 \\
+\quad 7.43 \\
9.5 \\
23.9\end{array}$ & $\begin{array}{c}40 \\
7.48 \\
7.6 \\
13.6\end{array}$ & $\begin{array}{r}\text { A } \\
7 \cdot 44 \\
6.4 \\
13.6\end{array}$ \\
\hline$(\mathrm{mmol} / \mathrm{l}$ & 53 & 53 & 54 & 57 & 47 & 43 & 33 \\
\hline
\end{tabular}

diuresis then occurred, with a fall in blood bicarbonate concentration. Also her initial hyperventilation had been replaced by hypoventilation with a fall in $\mathrm{PO}_{2}$, and therefore oxygen was given by facemask. The table gives the blood gas results. After resuscitation gastroscopy showed a large ulcer in the duodenal cap causing stenosis. She was referred for surgery and eventually made a good recovery.

\section{Comment}

The severe chronic metabolic alkalosis in this patient was accompanied by severe hyperlactataemia. This association has not been described previously, though small increases in blood lactate concentration have been shown to occur in acute respiratory and metabolic alkalosis in both animals and man and in chronic metabolic alkalosis in animals. ${ }^{1}$

The acid-base values on admission were compatible with a combined metabolic and respiratory alkalosis. The metabolic alkalosis was due to loss of gastric acid. The $\mathrm{PCO}_{2}$, which is often increased in metabolic alkalosis, was slightly low. The mild degree of hyperventilation, as opposed to the expected hypoventilation, was probably the result of hypotension stimulating peripheral chemoreceptors. Correction of this resulted in an appropriate compensatory respiratory acidosis. Tissue hypoxia is the commonest cause of increased lactate production. ${ }^{2}$ In this case, however, hypoxaemia was not present initially and, though peripheral perfusion was reduced, the degree of hyperlactataemia was greater than would have been predicted from the haemodynamic disturbance. The cause of the hyperlactataemia in this case must remain speculative. It may have been due to the effect of severe alkalosis either on the haemoglobin-oxygen dissociation curve, which combined with the low haemoglobin concentration would cause tissue hypoxia, or on the metabolic pathways leading to lactate accumulation, as has been described. ${ }^{3}$

As blood taken for lactate estimation requires specially prepared sample tubes, usually containing a protein precipitant, this estimation is infrequently requested; hence the association of chronic metabolic alkalosis and hyperlactataemia might have gone unrecognised. Certainly patients with metabolic alkalosis have been reported with considerably increased anion gaps for which no explanations have been offered, ${ }^{45}$ though small increases in the anion gap occur in alkalosis owing to the increased negative charge carried on plasma proteins. Admittedly, in this patient it is not possible to explain all the findings, though there were many features which together would have an additive effect in producing hyperlactataemia. A comprehensive study of further cases of severe metabolic alkalosis would be of value to define whether hyperlactataemia is a frequent accompaniment and if so by what mechanism the hyperlactataemia arises.

1 Madias NE. Lactic acidosis. Kidney Int 1986;29:752-74.

2 Cohen RD, Woods HF. Clinical and biochemical aspects of lactic acidosis. Oxford: Blackwell Scientific, 1976.

3 Relman AS. Metabolic consequences of acid-base disorders. Kidney Int 1972;1:347-59.

4 Lifschitz MD, Brasch R, Cuomo AJ, Mann SJ. Marked hypercapnia secondary to severe metabolic alkalosis. Ann Intern Med 1972;77:405-9.

Beach FXM, Sherwood Jones E. Metabolic alkalosis treated with intravenous hydrochloric acid. Postgrad Med f 1971;47:516-20.

(Accepted 27 February 1987)

University Hospital of South Manchester, West Didsbury, Manchester M20 8LR

R H NEARY, MB, MRCPATH, senior registrar in chemical pathology

J D EDWARDS, MB, MRCP, consultant physician

Correspondence to: Dr Neary.

\section{Are routine bacteriological cultures necessary in an accident and emergency department?}

Despite escalating costs and the limitations of financial resources use of laboratory services is rising rapidly: over 10 years workloads in radiology and pathology have increased by $80 \%$. $^{1}$ Stilwell $e t a l$, in evaluating laboratory tests in hospitals, confirmed that many tests were requested thoughtlessly, wasting resources ${ }^{2}$; Sandler showed that routine examination of blood and urine contributed to only $1 \%$ of the diagnosis. ${ }^{3}$

Microbiology services receive many requests that cannot reasonably be expected to influence management of patients; a high proportion of these come from the accident and emergency departments. Requests are commonly for culture and assessment of antibiotic sensitivity of pus swabs, usually taken from an infected wound or an incised localised abscess. In most cases, however, no antibiotics are prescribed and patients have a short follow up. This study was undertaken to evaluate the usefulness of taking bacteriological swabs in the accident and emergency department of a district general hospital.

\section{Methods and results}

Microbiological reports on all bacteriological swabs taken from patients attending the accident and emergency department over three months were examined. During this period one swab was taken from each of 275 patients (176 men, 99 women; age range $1-82$, mean 28.6 years). In 156 cases swabs were from a cutaneous abscess that required incision and drainage and in 119 they were from fresh or healing wounds that were thought to be infected.

Appreciable bacteriological growth was reported for 175 swabs: Staphylococcus aureus (134), $\beta$ haemolytic streptococcus (15), $S$ aureus plus Escherichia coli (10), $S$ aureus plus $\beta$ haemolytic streptococcus (six), and others (10); in the remaining 100 either there was no growth or the growth was slight. Of the pathogens isolated, $99 \%$ were sensitive to erythromycin and $86 \%$ to flucloxacillin.

Of the 156 patients with an abscess, 35 were taking antibiotics prescribed by their general practitioner and 15 others were given antibiotics as part of the initial treatment (in five as a necessary adjunct to drainage as the abscess was close to the periorbital area and there was a danger of spreading cellulitis, but for no clear 
reason in 10). Ten patients were treated surgically and then given antibiotics; the remaining 96 patients did not receive any antibiotics. Altogether 139 patients with an abscess (89\%) were discharged within seven days of their initial treatment.

Of the 119 patients without an abscess, nine with animal bites were given antibiotics when the bacteriology results were available and four with compound digital fractures were given long courses of antibiotics because of suspected bony infection.

\section{Comment}

Altogether 38 out of 275 patients (14\%) were given antimicrobial treatment in hospital; in only nine cases $(3 \%)$ was the treatment based on the result of culture and antibiotic sensitivity. In over $60 \%$ of cases the patient was discharged before the results of culture were available; in another $25 \%$, despite prolonged follow up, the result was not recorded. This practice is similar to that in other accident and emergency departments, indicating that routine sampling for microbiological testing is unnecessary.

Early and thorough debridement is the most important factor in preventing infection in traumatic wounds. Successful treatment of an established infection depends on early diagnosis and accurate localisation of the sepsis followed by incision and adequate drainage; antibiotics are not then usually necessary. In patients in whom antibiotics are thought to be desirable-for example, those at high risk and those with signs of spreading cellulitis or systemic infection-there are usually sufficient clinical signs to indicate the likely infecting organism and its sensitivity, thus making laboratory confirmation unnecessary. ${ }^{34}$ Laboratory studies have confirmed that erythromycin and flucloxacillin are active against the most commonly implicated pathogens. ${ }^{5}$ Bacteriological examination should be confined to patients with periorbital infection or human and animal bites (particularly near joints) and those in whom drainage alone may not eradicate infection from the surrounding tissue.

1 Young DW. An aid to reducing unnecessary investigations. BrMed f 1980;281:1601-11. Stilwell JA, Young D, Cunnington A. Evaluation of laboratory tests in hospitals. Ann Clin Biochem 1980;17:281-6.

3 Sandler G. Cost of unnecessary tests. Br Med f 1979;ii:201-4.

4 Jones AG, Wilson DH. The treatment of acute abscesses by incision, curettage and primary suture under antibiotic cover. $B r f$ Surg 1976;63:499-501.

5 Hassam ZA, Shaw E, Shooter RA, Caro DB. Changes in antibiotic sensitivity in strains of staphylococcus aureus, 1952-78. BrMed f 1978;ii:536-7.

(Accepted 27 February 1987)

Accident and Emergency Department, Walsall General Hospital, Walsall, West Midlands WS1 3QY

KAMBIZ HASHEMI, FRCS, senior registrar

MIKE MERLIN, FRCS, consultant

Correspondence to: Mr K Hashemi, Accident and Emergency Department, Mayday Hospital, Thornton Heath, Surrey CR4 7YE.

\section{Herpes zoster of second and third segments causing ipsilateral Horner's syndrome}

Herpes zoster, an infection of the first sensory neurone and its corresponding area of skin, usually affects ganglia of the dorsal root and the fifth and seventh cranial nerves. It may also cause other neurological complications, such as motor paralysis, myelitis, encephalitis, cranial nerve paralysis, pupillary abnormalities, diaphragmatic paralysis, polyneuritis, and contralateral hemiparesis. ${ }^{1-3}$ We describe a case of Horner's syndrome presenting as a complication of herpes zoster of the second and third thoracic segments.

\section{Case report}

A previously healthy 46 year old man presented in July 1984 with drooping of the right eyelid. Two weeks before he had developed a painful rash over his right scapula and in his right axilla. This had the typical appearance of shingles. He had also noticed a slight redness of the right eye with drooping of the eyelid. The redness had settled within a few days but the ptosis had persisted. In addition, he had noticed that the right side of his face was warmer and drier than the left.

Examination showed healing scars of herpes zoster over the distribution of the second and third thoracic segments on the back of his chest and in his right axilla running down towards the medial side of his arm. There was partial ptosis, miosis, and apparent enopththalmos of the right eye. The right side of his face felt less moist than the left. There was no finger clubbing or cervical lymphadenopathy or any evidence of pulmonary abnormalities.

Haematological and biochemical investigations yielded normal results. Radiographs of the chest taken in October 1984 and in August 1985 showed no abnormality.

Pupillary reaction was tested with $2 \%$ homatropine hydrobromide, $4 \%$ cocaine hydrochloride, and $1 \%$ adrenaline eye drops (figure).

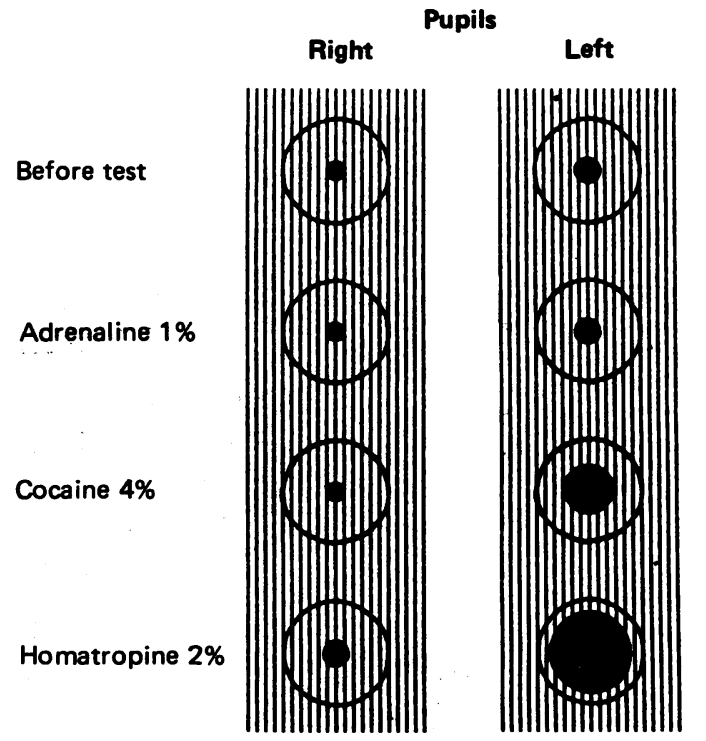

Approximate pupillary sizes of both eyes during test. (Vertical lines are about $1 \mathrm{~mm}$ apart.)

\section{Comment}

Horner's syndrome, or ocular sympathetic paresis, occurs when there is interruption of the sympathetic pathway at any point from the hypothalamus, brain stem, spinal cord, sympathetic chain, stellate ganglion, or sympathetic plexus along the internal carotid artery and the ocular sympathetic fibres. It is, therefore, difficult to locate the exact lesion in Horner's syndrome. Studying the pupillary reaction to adrenaline may help to differentiate between preganglionic and postganglionic lesions. In postganglionic lesions adrenaline causes dilatation of the pupil because of denervation hypersensitivity. If the lesion is preganglionic the size of the pupil will not change. ${ }^{4}$ Pupillary response to other substances, such as cocaine, which inhibits the uptake of noradrenaline, may help to differentiate a peripheral from a central cause. If the lesion is within the central nervous system the pupil will dilate, whereas if the lesion is peripheral there will be no response. ${ }^{5}$

Our patient had hemifacial anhydrosis, and the results of pupillary tests suggested a preganglionic lesion localised to the second order neurone which stretches from the lateral horn of the upper thoracic segments (T1-T4) to the cervical sympathetic ganglia. He also had a herpetic skin rash in the distribution of the second and third thoracic nerves on the same side as his Horner's syndrome. The combination of these findings leaves little doubt that in this patient the Horner's syndrome was due to herpes zoster affecting the sympathetic fibres at the level of T1-T3.

1 Kendall D. Motor complications of herpes zoster. $\mathrm{Br}$ Med $\mathcal{~}$ 1957; ii:616-8.

2 Gardner-Thorpe C, Foster JB, Barwick DD. Unusual manifestations of herpes zoster. A clinical and electrophysiology study. $\mathcal{J}$ Neurol Sci 1976;28:427.

3 Reshef E, Greenberg SB, Jankovic J. Herpes zoster ophthalmics followed by contralateral hemiparesis: report of two cases and review of literature. I Neurol Neurosurg Psychiatry 1985;48:122-7. 4 Thompson HS, Mensher JH. Adrenergic mydriasis in Horner's syndrome. Am $\mathcal{f}$ Ophthalmol

5 Jaffe NS. Localisation of lesions causing Horner's syndrome. Arch Ophthalmol 1950;44:710-28.

(Accepted 6 March 1987)

Regional Centre for Neurology and Neurosurgery, Oldchurch Hospital, Romford RM7 0BE

H S K WIMALARATNA, MRCP, research fellow

R CAPILDEO, MB, MRCP, consultant neurologist

Orsett Hospital, Grays, Essex

H Y LEE, MRCP, consultant physician

Correspondence to: Dr Wimalaratna. 